\title{
PENERAPAN MULTI-OBJECTIVE OPTIMIZATION ON THE BASIS OF RATIO (MOORA) DALAM PENENTUAN ASISTEN LABORATORIUM
}

\section{L.M. Fajar Israwan}

Program Studi Teknik Informatika

Universitas Dayanu Ikhsanuddin, Bau-Bau, Sulawesi Tenggara, Indonesia

fajarisrawan@unidayan.ac.id

\begin{abstract}
ABSTRAK
Penerimaan asisten laboratorim merupakan tahap proses perekrutan yang dilakukan oleh penanggung jawab lab, terdapat beberapa kriteria yang dijadikan patokan penilaian dari kualifikasi masing-masing calon asisten yang melamar. Penelitian ini bertujuan untuk menerapkan Meotde Multi-Objective Optimization on The Basis Of Ratio (MOORA) dalam penentuan aisten laboratorium. Terdapat 3 kriteria yaitu Nilai Ujian, Indeks Prestasi dan Semester. Alternatif dengan rangking nomor 1 merupakan alternatif dengan nilai tertinggi pada perhitungan Metode Moora.
\end{abstract}

Kata Kunci : Asisten, Laboratorium, Moora, Perekrutan

\begin{abstract}
Acceptance of laboratory assistants is the stage of the recruitment process carried out by the person in charge of the lab, there are several criteria used as a benchmark for the assessment of the qualifications of each prospective assistant who applies. This study aims to apply the Multi-Objective Optimization Meotde on The Base Of Ratio (MOORA) in determining laboratory assistant. There are 3 criteria, namely Exam Value, Achievement Index and Semester. The alternative with number 1 ranking is the highest value alternative in calculating the Moora Method.
\end{abstract}

Keywords: Assistant, Laboratory, Moora, Recruitment. 


\section{PENDAHULUAN}

Salah satu kegiatan akademik yang mendukung perkuliahan yaitu praktikum pada laboatorium. Kegiatan ini dimaksudkan untuk mengembangkan kompetensi motorik mahasiswa pada beberapa matakuliah. Proses kegiatan praktikum melibatkan asisten praktikum atau asisten laboratorium. Asisten ini merupakan mahasiswa yang dipilih melalui seleksi untuk pengembangan tugas membimbing praktikan dalam kegiatan praktikum [1].

Penerimaan asisten merupakan tahap proses perekrutan yang dilakukan oleh penanggung jawab laboratorium, dalam tahap perekrutan asisten terdapat beberapa kriteria yang dijadikan patokan penilaian dari kualifiasi yang dimiliki oleh masingmasing calon asisten yang melamar [2].

Proses seleksi dari beberapa kriteria dan alternatif merupakan salah satu cabang analisa keputusan pada Multi Criteria Decision Making (MCDM). Umumnya setiap altenatif memiliki kelebihan dan kelemahan yang membuat pengambil keputusan sukar dalam menentukan pilihan [3].

Dalam MCDM terdapat banyak metode, salah satunya adalah Multi-Objective Optimization on The Basis of Ratio (MOORA). MOORA adalah metode yang memiliki perhitungan dengan kalkulasi yang minimum dan sangat sederhana. Metode ini memiliki tingkat selektifitas yang baik dalam menentukan suatu alternatif. Pendekatan yang dilakukan MOORA didefinisikan sebagai suatu proses secara bersamaan guna mengoptimalkan dua atau lebih yang saling bertentangan pada beberapa kendala [4].

Penelitian ini bertujuan untuk menerapkan Metode MOORA dalam penentuan asisten laboratorium, sehingga akan memudahkan pihak penanggung jawab laboratorium dalam menseleksi asisten.

\section{TINJAUAN PUSTAKA}

\subsection{Asisten Laboratorium}

Asisten Lab praktikum adalah mahasiswa yang telah mendaftarkan dirinya dan terpilih untuk menjadi asisten dosen matakuliah praktikum tertentu sesuai yang dipilih.

Adapun tugas asisten lab praktikum adalah sebagai berikut:

1) Menyiapkan materi praktikum sebelum proses perkuliahan lab dimulai.

2) Menyampiakan materi yang akan dipraktikumkan.

3) Membuat soal atau tugas praktikum untuk mahasiswa praktikannya.

4) Memberikan penilaian harian (tes, praktikum dan laporan) terhadap mahasiswa praktikan.

\subsection{Sistem Pendukung Keputusan}

Decison Support System (DSS) atau dikenal juga dengan istilah Sistem Pendukung Keputusan (SPK) pertama kali diperkenalkan oleh Scott Morton pada awal tahun 1970-an. DSS didefinisikan sebagai sistem berbasis komputer interaktif yang membantu para pengambil keputusan untuk menggunakan data dan berbagai model untuk memecahkan masalahmasalah semi terstruktur atau tidak terstruktur [5].

Tahapan SPK:

1) Definisi masalah

2) Pengumpulan data atau elemen informasi yang relevan

3) Pengolahan data menjadi informasi baik dalam bentuk laporan grafik maupun tulisan

4) Menentukan alternatif-alternatif solusi

Tujuan dari SPK:

1) Membantu menyelesaikan masalah semiterstruktur

2) Mendukung manajer dalam mengambil keputusan suatu masalah

3) Meningkatkan efektifitas bukan efisiensi pengambilan keputusan

\subsection{Rank Order Centroid (ROC)}

Metode ROC digunakan untuk menetukan nilai bobot tiap kriteria. Perhitungan ROC didasarkan pada tingkat kepentingan atau prioritas dari kriteria, teknik ROC memberikan bobot pada setiap kriteria sesuai dengan ranking yang dinilai berdasarkan tingkat prioritas. Biasanya dibentuk dengan pernyataan "Kriteria 1 lebih penting dari kriteria 2, yang lebih penting dari kriteria 3" dan seterusnya hingga kriteria ke $n$. Untuk menentukan prioritasnya, diberikan aturan yaitu dimana nilai tertinggi merupakan nilai yang paling penting diantara nilai yang lainnya.

Jika $\mathrm{C}$ adalah Kriteria

$\mathrm{Cr}_{1} \geq \mathrm{Cr}_{2} \geq \mathrm{Cr}_{3} \geq \ldots \geq \mathrm{C}_{\mathrm{m}}$

Maka Bobot Kriteria (W),

$$
\mathrm{W}_{1} \geq \mathrm{W}_{2} \geq \mathrm{W}_{3} \geq \ldots \geq \mathrm{W}_{\mathrm{n}}
$$

Selanjutnya, jika k merupakan banyaknya kriteria, maka

$$
\begin{aligned}
& \mathrm{W}_{1}=\frac{1+\frac{1}{2}+\frac{1}{3}+\ldots+\frac{1}{k}}{k} \\
& \mathrm{~W}_{2}=\frac{0+\frac{1}{2}+\frac{1}{3}+\ldots+\frac{1}{k}}{k} \\
& \mathrm{~W}_{3}=\frac{0+0+\frac{1}{3}+\ldots+\frac{1}{k}}{k}
\end{aligned}
$$




$$
\mathrm{W}_{\mathrm{k}}=\frac{0+\cdots+0+\frac{1}{k}}{k}
$$

Secara umum pembobotan ROC dapat dirumuskan sebagai berikut:

$$
\mathrm{W}_{\mathrm{k}}=\frac{1}{k} \sum_{i=1}^{k}\left(\frac{1}{i}\right)
$$

\subsection{MOORA}

Metode Multi-Objective Optimization by Ratio Analysis (Moora) adalah metode yang diperkenalkan oleh Brauers dan Zavadkas (2006) [6]. Metode yang relatif baru ini pertama kali digunakan oleh Brauers pada tahun 2003 dalam suatu pengambilan dengan multi-kriteria. Metode Moora memiliki tingkat fleksibilitas dan kemudahan untuk dipahami dalam memisahkan bagian subjektif dari suatu proses evaluasi kedalam kriteria bobot keputusan dengan beberapa atribut pengambilan keputusan.

Metode Moora mudah dipahami dan fleksibel dalam memisahkan objek hingga proses evaluasi kriteria bobot keputusan. Metode Moora juga memiliki tingkat selektifitas yang baik karena dapat menentukan tujuan dan kriteria yang bertentangan, yaitu kriteria yang bernilai menguntungkan (Benefit) atau yang tidak menguntungkan (Cost). Adapun langkah-langka perhitungan MOORA adalah sebagai berikut:

1) Buat sebuah Matrik keputusan

$$
x=\left[\begin{array}{lll}
x_{11} & x_{12} & x_{1 n} \\
x_{21} & x_{22} & x_{2 n} \\
x_{m 1} & x_{m 1} & x_{m n}
\end{array}\right]
$$

2) Melakukan normalisasi terhadap matrik $x$

$$
x_{i j}^{*}=\frac{x_{i j}}{\sqrt{\left[\sum_{i=1}^{m} x_{i j}^{2}\right](j=1,2, \ldots n)}}
$$

3) Mengoptimalkan Atribut

$$
y_{i}=\sum_{j=1}^{g} x_{i j}^{*}-\sum_{j=g+1}^{n} x_{i j}^{*}
$$

4) Apabila menyertakan bobot dalam pencarian yang ternormalisasi maka persamannya

$$
y_{i}=\sum_{j=1}^{g} w_{j} x_{i j}^{*}-\sum_{j=g+1}^{n} w_{j} x_{i j}^{*}
$$

\section{METODE YANG DIUSULKAN}

Prosedur penelitian ditunjuakan pada gambar 3.1 berikut ini:

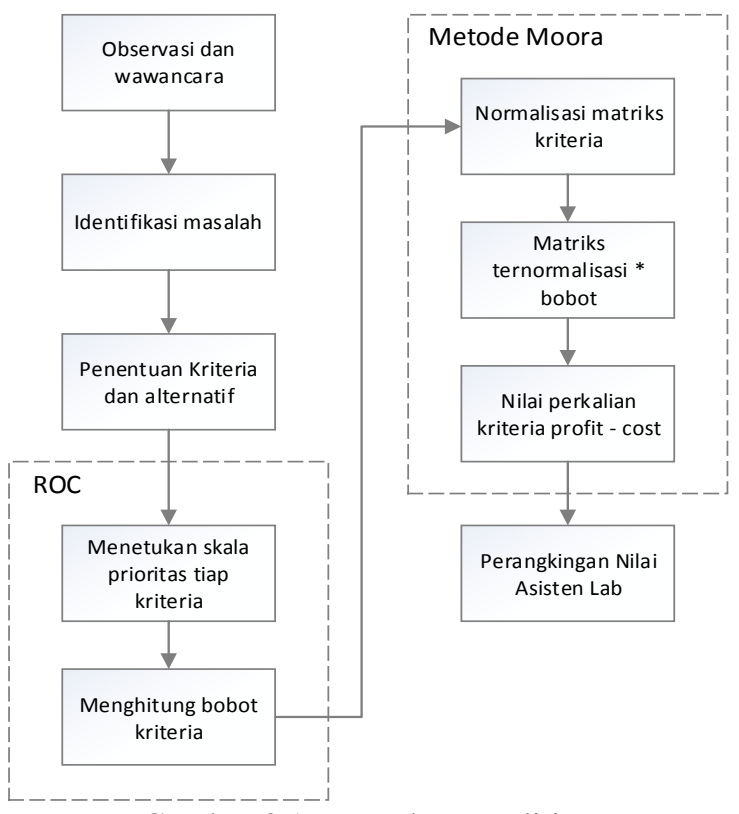

Gambar 3.1. Prosedur Penelitian

Penelitian dimulai dari melakukan observasi dan wawancara kepada pihak laboratorium untuk mengumpulkan data awal dalam mengidentifikasi masalah, sehingga dapat ditetapkan kriteria dan alternatif yang akan dinilai. Selanjutnya yaitu menghitung nilai bobot dari tiap kriteria menggunakan Metode ROC. Untuk menghitung bobot, terlebih dahulu mementukan skala prioritas dari tiap kriteria, pada penelitian ini terdapat 3 kriteria penilaian secara berurut yaitu Nilai ujian seleksi (Profit), Indeks Prestasi (Profit) dan Semester (Cost). Perhitungan bobot menggunakan persamaan 2.1

Implementasi metode Moora diawali dengan membuat matriks keputusan kemudian melakukan normalisasi kriteria menggunakan persamaan 2.3, selanjutnya matrik ternormalisasi dikaliakan dengan bobot kriteria dan mengurangkan nilai hasil perkalian antara kriteria benefit dan cost.

Adapun data kriteria dan alternatif ditunjukan pada tabel 3.1 berikut ini:

Tabel 3.1. Data asisten laboratorium

\begin{tabular}{rlccc}
\hline No & Nama & NU & IPK & Smtr \\
\hline 1 & HENDRIK BAKRI & 85 & 3,4 & 4 \\
2 & RAHMAN & 70 & 3,2 & 4 \\
3 & ALIF APRIANTO & 85 & 3,5 & 4 \\
4 & VINDA & 80 & 3,8 & 6 \\
5 & NUR ASMI & 70 & 3,2 & 6 \\
6 & ADITIYA RESKI & 65 & 3,3 & 6 \\
\hline
\end{tabular}




\section{HASIL PENELITIAN}

\subsection{Perhitungan Bobot Kriteria}

Perhitungan bobot kriteria menggunakan metode ROC yaitu sebagai berikut:

Nilai Ujian $=(1+1 / 2+1 / 3) / 3=0,610$

IPK $=(1 / 2+1 / 3) / 3=0,277$

Semester $(1 / 3) / 3=0,110$

\subsection{Implementasi Moora}

Adapun tahap dari perhitungan Moora adalah sebagai berikut:

1. Membuat Matriks Kepeutusan

$$
x=\left[\begin{array}{ccc}
85 & 3,4 & 4 \\
70 & 3,2 & 4 \\
85 & 3,5 & 4 \\
80 & 3,8 & 6 \\
70 & 3,2 & 6 \\
65 & 3,3 & 6
\end{array}\right]
$$

2. Normalisasi Matriks

a) Normalisasi kriteria nilai ujian

$$
\begin{aligned}
& C_{1}=\sqrt{85^{2}+70^{2}+85^{2}+80^{2}+70^{2}+65^{2}} \\
& =\sqrt{34875}=186,75 \\
& A_{1} C_{1}=85 / 186,75=0,4552 \\
& A_{2} C_{1}=70 / 186,75=0,3748 \\
& A_{3} C_{3}=85 / 186,75=0,4552 \\
& A_{4} C_{1}=80 / 186,75=0,4284 \\
& A_{5} C_{1}=70 / 186,75=0,3748 \\
& A_{6} C_{1}=65 / 186,75=0,3481
\end{aligned}
$$

b) Normalisasi kriteria IPK

$$
\begin{aligned}
& C_{2}=\sqrt{3,4^{2}+3,2^{2}+3,5^{2}+3,8^{2}+3,2^{2}+3,3^{2}} \\
& =\sqrt{69,62}=8,34 \\
& A_{1} C_{2}=3,4 / 8,34=0,4077 \\
& A_{2} C_{2}=3,2 / 8,34=0,3837 \\
& A_{3} C_{2}=3,5 / 8,34=0,4197 \\
& A_{4} C_{2}=3,8 / 8,34=0,4556 \\
& A_{5} C_{2}=3,2 / 8,34=0,3837 \\
& A_{6} C_{2}=3,3 / 8,34=0,3957
\end{aligned}
$$

c) Normalisasi kriteria Semester

$$
\begin{gathered}
C_{3}=\sqrt{4^{2}+4^{2}+4^{2}+6^{2}+6^{2}+6^{2}} \\
=\sqrt{156}=12,49 \\
A_{1} C_{3}=4 / 12,49=0,3203 \\
A_{2} C_{3}=4 / 12,49=0,3203 \\
A_{3} C_{3}=4 / 12,49=0,3203 \\
A_{4} C_{3}=6 / 12,49=0,4804 \\
A_{5} C_{3}=6 / 12,49=0,4804 \\
A_{6} C_{3}=6 / 12,49=0,4804
\end{gathered}
$$

3. Perkalian Matriks Ternormalisasi dengan Bobot

a) Kriteria Profit

$\left[\begin{array}{ll}(0,4552 * 0,61) & (0,4077 * 0,277) \\ (0,3748 * 0,61) & (0,3837 * 0,277) \\ (0,4552 * 0,61) & (0,4197 * 0,277) \\ (0,4284 * 0,61) & (0,4556 * 0,277) \\ (0,3748 * 0,61) & (0,3837 * 0,277) \\ (0,3481 * 0,61) & (0,3957 * 0,277)\end{array}\right]$

$$
=\left(\begin{array}{ll}
0,2776 & 0,1128 \\
0,2286 & 0,1062 \\
0,2776 & 0,1161 \\
0,2613 & 0,1261 \\
0,2286 & 0,1062 \\
0,2123 & 0,1095
\end{array}\right)
$$

b) Kriteria Cost

$$
\left(\begin{array}{l}
0,3203 * 0,11 \\
0,3203 * 0,11 \\
0,3203 * 0,11 \\
0,4804 * 0,11 \\
0,4804 * 0,11 \\
0,4804 * 0,11
\end{array}\right)=\left(\begin{array}{l}
0,0352 \\
0,0352 \\
0,0352 \\
0,0528 \\
0,0528 \\
0,0528
\end{array}\right)
$$

4. Kriteria Benefit - Cost

Hasil perangkingan didapat dari pengurangan nilai kirteria Benefit dengan kriteria

\begin{tabular}{llcccc}
\multicolumn{1}{l}{ Cost. } \\
\hline NO & \multicolumn{1}{l}{ NAMA } & MAX C1+C2 & MIN C3 & Y(MAX-MIN) & RANK \\
\hline 1 & HENDRIK BAKRI & 0,3904 & 0,0352 & 0,3552 & 2 \\
2 & RAHMAN & 0,3348 & 0,0352 & 0,2996 & 4 \\
3 & ALIF APRIANTO & 0,3938 & 0,0352 & 0,3585 & 1 \\
4 & VINDA & 0,3874 & 0,0528 & 0,3345 & 3 \\
5 & NUR ASMI & 0,3348 & 0,0528 & 0,2820 & 5 \\
6 & ADITIYA RESKI & 0,3218 & 0,0528 & 0,2689 & 6 \\
\hline
\end{tabular}

\section{KESIMPULAN}

Dengan menerapkan metode Moora pada pemilihan asisten laboratorium maka proses seleksi 
akan menjadi lebih obyektif, alternatif dengan rangkin nomor 1 adalah alternatif dengan nilai tertinggi dari perhitungan metode Moora.

\section{Daftar Pustaka}

[1] Yaya Sulviyana, Andi Tejawati, Ummul Hairah., 2017, Sistem Pendukung Keputusan Seleksi Penerimaan Calon Asisten Praktikum Menggunakan Metode SMART, Prosiding Seminar Nasional Ilmu Komputer dan Teknologi Informasi Vol. 2, No. 2, e-ISSN 2540-7902 dan p-ISSN 2541-366

[2] Auliya Rahman Isnian, Suaidah, Yohana Tri Utami., 2016, Sistem Pendukung Keputusan Penerimaan Asisten Dosen Pada Perguruan Tinggi Teknokrat Menggunakan Metode Analytical Hierarchy Process (AHP), Jupiter, 2(1).

[3] Jani Rahardjo, Ronald E. Stok, Rosa Yustina., 2000, Penerapan Multi-Criteria Decision Makingdalam Pengambilan Keputusan Sistem Perawatan, Jurnal Teknik Industri Vol. 2, No. $1-12$.

[4] S. Rokhman, I. F. Rozi, and R. A. Asmara., 2017, Pengembangan Sistem Penunjang Keputusan Penentuan UKT Mahasiswa Dengan Menggunakan Metode MOORA Studi Kasus Politeknik Negeri Malang," J. Inform. Polinema, Vol. 3, 36-42.

[5] Turban, E., 2005, Decision Support Systems and Intelligent Systems Edisi Bahasa Indonesia Jilid 1, Andi Offset, Yogyakarta.

[6] M. Ashari and F. Mintarsih., 2017, Aplikasi Pemilihan Bibit Budidaya Ikan Air Tawar dengan Metode MOORA - Entropy, J. Sist. Inf., Vol. 5341, pp. 63-73. 